\title{
EDUCAÇÃO AMBIENTAL E A EDUCAÇÃO ALIMENTAR: OS SABERES NO CAMPO DAS PRÁTICAS EDUCATIVAS
}

\author{
Simone Teles da Silva Santos ${ }^{1}$ \\ Avelar Luiz Bastos Mutim²
}

\begin{abstract}
Resumo: Este artigo teve como objetivo apontar quais são as práticas pedagógicas para o ensino-aprendizagem no desenvolvimento de Educação Ambiental sobre educação alimentar, para os alunos de escola pública de ensino infantil e fundamental I. Trata-se de pesquisa de campo, expondo abordagem qualitativa e entrevistas semiestruturadas e para analisar as informações utilizou-se a análise de conteúdo. A Educação Ambiental (EA) está diretamente vinculada ao ensino de educação alimentar como foi apresentado pelas professoras. Deve-se estreitar o discurso de Educação Ambiental e alimentação escolar norteada pelas práticas educativas de forma disciplinar e transversal, ampliando a propostas de EA, reconhecendo-se a educação alimentar e nutricional como parte do ensino para que se construa o "bemviver".
\end{abstract}

Palavras-chave: Alimentação Saudável; Prática Educativa; Meio Ambiente; Sensibilização.

Abstract: This article aimed to point out what are the pedagogical practices for teaching-learning in the development of environmental education on food education, for public school children of elementary and elementary school I. It is a field research, exposing a qualitative and semi-structured interview and to analyze the information, content analysis was used. Environmental education (AE) is directly linked to the teaching of food education as presented by the teachers. The discourse of environmental education and school feeding guided by educational practices should be narrowed in a disciplinary and transversal way, expanding the proposals of $E E$, recognizing food and nutrition education as part of teaching so that "well-being" is built.

Keywords: Healthy Eating; Educational Practice; Environment; Awareness.

\footnotetext{
1 Universidade do Estado da Bahia/UNEB. E-mail: Simone.teles.silva@gmail.com. Link para o Lattes: http://lattes.cnpq.br/8378440652964246.

2 Universidade do Estado da Bahia/UNEB. E-mail: amutim@uneb.br.

Link para o Lattes: http://lattes.cnpq.br/1466202330245628.
} 


\section{Introdução}

Os estudos sobre Educação Ambiental (EA) alegadamente podem influenciar nas atitudes do ser humano. Dessa forma, a origem dos conceitos presentes nos projetos programas e leis que vigoram até os dias atuais são interpretados com diferenciações nos espaços educativos escolares.

A Educação Ambiental é regulamentada pela Lei Federal, n. 9 795/99 e no seu artigo $2 .^{\circ}$ é determinada como componente essencial e permanente da educação nacional, devendo estar presente de forma articulada em todos os níveis e modalidades do processo educativo, em caráter formal e não formal (BRASIL, 1999). Por conseguinte, estabeleceram-se projetos mais precisos desvelando que a segurança alimentar está vinculada a EA, e deste modo, a fim de assegurar a sobrevivência humana. Para tanto, a definição de programas com temáticas de segurança alimentar foi constituída. Segundo Lima, Magalhães e Fonseca (2012) são com estas estruturas que terão que lidar com a complexa luta pelo direito humano à alimentação derivada do crescente sistema agroalimentar mundial.

O fortalecimento da Educação Alimentar e Nutricional culminou-se na Lei $n . .11$ 947, de 2009: "a inclusão da educação alimentar e nutricional no processo de ensino e aprendizagem, perpassa pelo currículo escolar, abordando o tema, alimentação, nutrição e o desenvolvimento de práticas saudáveis [...]" (BRASIL, 2012, p. 19).

Sabe-se que o ensino de Educação Ambiental abrange diversidade de espaços formais e não-formais, e o uso indiscriminado de agrotóxico nas plantações, o desmatamento e a utilização desregrada da água são temas abrangentes, que provocam preocupações, sendo necessário projetar melhor o ensino de Educação Ambiental e a prática educativa na escolarização pontuando sobre a prática dos saberes de professoras que atuam em escolas públicas, o ensino desenvolvido na sala de aula, inquietações que permeiam o campo de entendimento proposto como Educação Ambiental.

As inquietações sobre quais práticas pedagógicas para o ensinoaprendizagem no desenvolvimento, de Educação Ambiental sobre educação alimentar para os alunos de escola pública de ensino infantil e fundamental I a partir de reflexão docente são desenvolvidas e insatisfações/satisfações existentes no processo em que é inferida qual prática educativa propiciou o objetivo. Portanto, este artigo teve como objetivo apontar quais as práticas pedagógicas para o ensino-aprendizagem no desenvolvimento da Educação Ambiental sobre educação alimentar para os alunos de escola pública de ensino infantil e fundamental I. 


\section{Referencial Teórico}

\section{Perspectivas da Educação Ambiental}

As vertentes do marco teórico da Educação Ambiental retratam que seu reconhecimento se deu após a conferência mundial sobre meio ambiente humano em 1972, onde aponta que a EA foi reconhecida politicamente a partir dessa data.

A Organização das Nações Unidas - ONU (1972) expõe na Declaração de Estocolmo sobre o Ambiente Humano, mantendo em seus princípios a deliberação de que é indispensável um esforço para a educação em questões ambientais, dirigida tanto às gerações jovens quanto aos adultos, prestando a devida atenção ao setor da população menos privilegiada, para fundamentar as bases de uma opinião pública bem informada e de uma conduta dos indivíduos das empresas e das coletividades inspiradas no sentido de sua responsabilidade sobre a proteção e melhoramento do meio ambiente em toda sua dimensão humana.

A Conferência das Nações Unidas sobre o Meio Ambiente Humano, reunida em Estocolmo acrescenta no princípio n. 19 que é igualmente essencial que os meios de comunicação de massas evitem contribuir para a deterioração do meio ambiente humano e, ao contrário, difundam informação de caráter educativo sobre a necessidade de protegê-lo e melhorá-lo, a fim de que o homem possa desenvolver-se em todos os aspectos.

É importante constatar que a prática educativa se faz necessária, primordialmente nos espaços em que o estudante é submetido, sendo então levados a adquirirem uma reciprocidade e respeito com a utilização dos recursos naturais. Por isso, faz-se necessária enquanto referencial para descoberta e/ou identificação de aspectos a formação de educadores em EA.

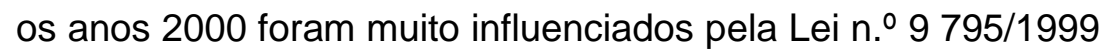
(que instituiu a Educação Ambiental), sendo o período mais efervescente da luta pelo fortalecimento da EA nas diferentes esferas da vida social. Nesse movimento, várias vozes (ambientalistas, órgãos governamentais ambientais, empresas, mídia e estudos) pressionavam intensamente as escolas e seus professores para que assumissem a responsabilidade para com o desenvolvimento de práticas de Educação Ambiental (OSÓRIO, 2011, p. 400).

Ressalta Osório (2011, p. 400 - 401), "alguns professores, interpelados por essas manifestações, buscavam responder aos apelos dos discursos da Educação Ambiental, mas não encontravam respostas em seu campo de ação: a educação". As unidades escolares devem então oferecer as crianças situações em que elas possam desenvolver todas as suas potencialidades para preservar, melhorando o meio ambiente. 
Segundo Osório (2011, p. 404) "[...] a Educação Ambiental não existe, no sentido de ser única, plena, neutra ou natural, ela é, ou torna-se, aquilo que fazemos dela a partir das diferentes práticas e dentro de relações que conjugam poder-saber [...]". Contribui com o modo de vida que se desenvolve mediante as práticas e, na contemporaneidade as práticas, aparecem com uma identidade própria. Os discursos sobre esse tema têm se aflorado principalmente nos espaços de processo educativo escolar. A Educação Ambiental permeia o campo de discussão nos processos educativos no que tange especificamente ao modo do ser humano de apreender sobre si e o mundo a sua volta.

\section{Prática educativa aspectos da formação de educadores}

É perceptível que no universo educacional, estratégias pedagógicas apoiem o trabalho dos profissionais da educação para com as crianças. Segundo Libâneo (2011, p. 88) "numa formulação sintética, boa didática significa um tipo de trabalho na sala de aula em que o professor atua como mediador da relação cognitiva do aluno com a matéria". Sugerir para o profissional da educação significativa proposta de trabalho em sala de aula, para que envolva seus educandos em circunstâncias de sucessivas construções ao longo do desenvolvimento, promove o direito e a ressignificação do ser.

Acrescenta Libâneo (2011, p. 88) "há uma condução eficaz na aula quando o professor assegura, pelo seu trabalho, o encontro bem-sucedido entre o aluno e a matéria de estudo". Por acreditar que o processo de aprendizagem é adquirido no ambiente educativo escolar e familiar, que os dois ambientes funcionam como viabilizadores da valorização e facilitadores do desenvolvimento desses alunos na sociedade e no contexto escolar.

Conforme Gimeno Sacristán (1999, p. 73) "a prática educativa é o produto a partir do qual os profissionais adquirem o conhecimento prático que eles poderão aperfeiçoar". À luz do exposto por Gimeno Sacristán, a prática exercida pode almejar o sucesso ou o insucesso, uma vez que este profissional não seja reconhecido no âmbito escolar como detentor de habilidades para executar sua função como tal.

Segundo Libâneo (2011, p. 88) "uma boa didática na perspectiva da mediação é aquela que promove e amplia o desenvolvimento das capacidades intelectuais dos alunos por meio dos conteúdos". Desse modo, preparam-se as aquisições seguintes, que se baseiam nas estruturas anteriores sendo de modo, preciso que o professor organize as condições para isso, uma delas e a mobilização da curiosidade dos alunos no início da aula, despertar a curiosidade, criar a consciência do problema proposto, a fim de que, eles percebam os objetivos da atividade, são ações necessárias para que em toda e qualquer aula as aprendizagens sejam significativas. 


\section{Enfoques da educação alimentar}

Para Goergen (2010), o pensar a educação, é dialógica e crítica. A linguagem assume outras condições, a educação passa a ser compreendida, no sentido, como espaço de reflexão de mundo, instância para o aperfeiçoamento, da educação política dos povos, articulações e suas inteligibilidades, perfazendo, portanto, um esforço teórico entre a filosofia e a pedagogia para a aproximação.

É notório, sendo um dos direitos conquistados seus pressupostos e suas definições transitam em permanência e um novo modo de vida nesse ambiente, a preocupação, para com o desenvolvimento da EA, e assim, num novo modo de educação. Relacionar a prática educativa aos processos de EA compreende-se 0 desenvolvimento intelectual que contribuem para 0 aprendizado; logo é de fundamental importância salientar que assegurar aos estudantes uma boa alimentação ajuda nesse desenvolvimento. Proporcionar alimentos saudáveis para os estudantes é também dever da escola. Nessa perspectiva é importante ressaltar, segundo Triches e Schneider (2010 p. 934)

\section{[...] o Programa Nacional de Alimentação Escolar (PNAE) aparecem como potenciais reintegradores desses componentes, em face das condições de auxiliar no enfrentamento das problemáticas referentes ao consumo e à produção de alimentos.}

Proporcionar às crianças hábitos saudáveis e uma alimentação rica em nutrientes é a oportunidade de interação para o seu desenvolvimento na aprendizagem, bem como o reconhecimento do ensino e aprendizagem nessa ação educativa; desvelamos lacunas deixadas nos aportes para melhorias e efetivação destas. "O Bem Viver - ou melhor, os bons conviveres - é uma oportunidade para construir um mundo diferente, que não será alcançado apenas com discursos estridentes, incoerentes com a prática" (ACOSTA, 2016, p. 21).

Ao buscar pressupostos legais que assegura a educação alimentar, encontram-se leis programas e projetos (Lei Orgânica de Segurança Alimentar e Nutricional - LOSAN (Lei 11. 346/2006); Lei de segurança Alimentar e Nutricional - SAN; e a Lei de Alimentação Escolar (11.947/2009) que deu origem ao Programa Nacional de Alimentação Escolar - PNAE. E Plano Estadual de Segurança Alimentar e Nutricional - PLANSAN) que se tornam políticas públicas e rege a vida das pessoas. Tais elaborações desenvolvidas pelos governos asseguram, mas por muito não se efetiva do modo que foi promulgado, restringindo, portanto, a disseminação da informação para com os processos educativos.

Conforme Triches e Schneider (2010, p. 934) "isso pela integração de políticas relacionadas à saúde das populações escolares e por outro, pela 
criação de mercados para os agricultores familiares, inclusive com potencial para fomentar práticas de gestão ambiental'. Segundo Acosta (2016, p. 21) "Outro mundo será possível se for pensado e erguido democraticamente, com os pés fincados nos Direitos Humanos e nos Direitos da Natureza".

Além disso, Roos e Becker (2012), afirmam que a EA é uma área que se dedica a buscar alternativas para a sensibilização da sociedade, utilizando a metodologia de ensino como instrumento norteador para mudanças de hábitos predatórios dos recursos naturais, de modo a garantir um desenvolvimento sustentável.

\section{Materiais e Métodos}

A tessitura epistemológica se adequou aos métodos e técnicas e aos instrumentos de pesquisa, tendo como método de estudo, a pesquisa de campo, embasado nos escritos de Gil (2006). Considerando o objeto de estudo a abordagem da pesquisa é qualitativa, que exerce um papel de natureza relevante, entre os campos de abordagens, mediante o que ressalta Richardson (2008, p.79), "a abordagem qualitativa de um problema, além de ser uma opção do investigador, justifica-se, sobretudo, por ser uma forma adequada para entender a natureza de um fenômeno social".

Lançamos mão da ferramenta entrevista semiestruturada, que, segundo Marconi; Lakatos (1982, p.70) é "um encontro entre duas pessoas, a fim de que uma delas obtenha informações a respeito de determinado assunto, mediante uma conversação de natureza profissional'. Desse modo, foram realizadas anotações.

A entrevista realizada com a professora da educação infantil ocorreu no período matutino em uma escola localizada no município de Bom Jesus da Lapa. Já a entrevista ocorrida com a professora do ensino fundamental I foi realizada no período vespertino em uma escola do município de Serra do Ramalho, municípios vizinhos situados no Oeste da Bahia. Ambos estão entre 778 a $842 \mathrm{~km}$ aproximadamente equidistantes da capital baiana.

As entrevistas foram realizadas na sala de aula da escola, locais de trabalho, onde as professoras exercem a função. Entendendo que o referido trabalho foi desenvolvido com sujeitos de duas escolas que se localizam em municípios próximos, as entrevistas ocorreram em períodos diferentes, mas no mesmo dia.

Atendendo a critérios de respeitar a integridade e a fidedignidade das professoras entrevistadas, obtivemos os cuidados necessários para entrevistálas separadamente de seus alunos. Nesse sentido, ocorreram as entrevistas nos intervalos de aula. O momento foi regado de observação e atenção a todas as situações postas durante a entrevista, assim como do espaço o qual a entrevista ocorreu. Em si tratando de entrevista onde o pesquisado está frente ao pesquisador, as anotações foram sendo realizadas em formato de rascunho no bloco de anotações para não perder a nenhuma informação. 
O roteiro de entrevista de início foi entregue às professoras a fim de que fizessem a leitura prévia e logo em seguida prosseguisse a entrevista direcionada pela pesquisadora com os questionamentos seguintes: a) Existem propostas pedagógicas para o ensino de Educação Ambiental na escola; b) Qual relação para você existe em Educação Ambiental e educação alimentar; c) De que modo estão relacionadas as práticas de ensino de Educação Ambiental e de educação alimentar; d) Como são desenvolvidas o ensino para os alunos tendo como relação a Educação Ambiental e a educação alimentar. Foram tabuladas e analisadas as informações.

Durante o momento foram questionadas as professoras e sanado possíveis dúvidas sobre as questões desferidas a elas. A atuação mesmo ocorrendo em momentos e locais diferentes foram procedidos da mesma forma, pois, buscou-se atrelar e conduzir os momentos para que não houvesse disparidades na condução e manejo do roteiro. As entrevistas tiveram questões não diferenciadas, mas buscou-se com isso referenciar a modalidade a qual as professoras atuam.

A partir do objetivo de apontar quais são as práticas pedagógicas para o ensino-aprendizagem no desenvolvimento de Educação Ambiental sobre educação alimentar, para os alunos de escola pública de ensino infantil e fundamental I.

Para tanto, foram entrevistadas 2 (duas) professoras, entre faixa etária de 28 a 38 anos de idade, uma especialistas em Mídias na Educação atuando em uma turma contendo 18 alunos na modalidade de educação infantil, e a outra em psicopedagogia atuando em duas turmas contendo no $3^{\circ}$ Ano 19 alunos e no $4^{\circ}$ Ano 26 alunos no ensino fundamental I, ambas na escola pública municipal.

Os requisitos para escolha das entrevistadas foram: o distanciamento das localidades, às quais estão as escolas localizadas, sendo uma na cidade e outra no campo (comunidade rural), outra característica que definiu a escolha foi a profissional da escola localizada na cidade ser pertencente à localidade origem (de nascimento) em comunidade do campo e a profissional que exerce função na escola de comunidade do campo ter origem (nascimento) na cidade.

As professoras que se dispuseram a participar da entrevista atenderam aos critérios, e diante da proposta de participação elucidada com a leitura e a cópia do termo de livre esclarecimento, o aceite espontâneo de ambas a participar, assim como específica para pesquisa com seres humanos a ética em pesquisa. No entanto, por se tratar de um ensaio para a formulação de pesquisa sobre a temática, essa proposta não está inscrita mesmo atendendo aos rigores éticos para pesquisa com seres humanos no comitê.

A análise das informações coletadas seguiu as especificidades que aponta Bardin (2006) para análise de conteúdo, em que o conteúdo das informações é apresentado a partir das transcrições, apontando nas informações pontos cruciais e identificando na transcrição das mensagens 
referentes à colheita nas entrevistas para o estudo sobre a efetivação e a aceitação da proposta.

Pontos temáticos de abordagens atribuídos no processo de ensino e aprendizagem ressaltando a aplicabilidade e efetividade na junção de temáticas que se acoplam da Alimentação Escolar (AE) atribuído aos conteúdos de EA, retratando as políticas sociais a partir da premissa de que expõe "o revelado na comunicação pelo conteúdo dos itens" (BARDIN 2006, p. $12)$, a partir da verificação de questões e descobertas do que está por trás dos conteúdos e manifestos.

\section{Resultados e discussão}

\section{"Aqui em minha sala a Educação Ambiental é desenvolvida": em minha prática de ensino}

Para as modalidades de ensino Infantil e fundamental I tivemos como objetivo apontar quais são as práticas pedagógicas para 0 ensinoaprendizagem no desenvolvimento de Educação Ambiental sobre educação alimentar, para os alunos de escola pública de ensino infantil e fundamental I. Concordando com o que enfatiza Osório (2011, p. 401) "meu foco está direcionado a destacar a Educação Ambiental como um instrumento de poder produzido e criado para modificar as condutas escolares e transformá-las de acordo com determinadas expectativas e esperanças". Atribui-se a entrevista direcionada a duas professoras uma de cada modalidade de ensino. A pesquisa parte do questionamento direcionado, sobre a proposta pedagógica na escola em que atuam. Existe uma proposta,

Sim. Em cada trimestre trabalhamos com um tema e o tema do segundo trimestre será Educação Ambiental. Procuramos também incluir em algumas datas comemorativas, para que a proposta se estenda durante todo o ano letivo. (professora da Educação Infantil. 12/04/2019).

Sim! Acreditamos que a Educação Ambiental discutida e estudada em sala de aula e nos espaços não formais de educação promova a conscientização crítica nos sujeitos sociais em suas práticas cotidianas. Para isso, se faz necessário o trabalho sistematizado pelo professor do ensino fundamental em todos os níveis. (professora do ensino fundamental I. 12/04/2019).

Conforme Lisboa, Kindel e Krob, um trabalho que procura auxiliar as escolas no desenvolvimento de atividades ambientais deve ser ampliado "[...] nos currículos de todas as escolas e em todos os seguimentos de ensino, buscando, sempre que possível, um enfoque interdisciplinar em que as questões ligadas ao ambiente sejam vivenciadas; [...] procure auxiliar as 
escolas quanto ao desenvolvimento de atividades ambientais" (LISBOA; KINDEL; KROB, 2012, p. 17).

Apesar da tomada de consciências nas pesquisas sobre EA no processo de aprendizagem, evidencia-se que "tanto no aspecto da definição do que educar como nos procedimentos pedagógicos" pode haver ensino, sem haver necessariamente aprendizagem. Um processo que precisa ser orientado, "que marca o conjunto das práticas educativas em suas diversas instâncias" Goergen (2010, p.55). Não estamos definindo graus de competência, mas que se tenha claro uma proposta e procedimentos para que a didática e o processo de conhecimento e aprendizagem seja significativa, as projeções de ações são necessárias e prudentes.

Em relação à Educação Ambiental e alimentar questionou-se o conhecimento sobre:

Vai desde o cuidado com o solo até a questão do lixo que produzimos por conta de alguns alimentos. Os dois estão interligados, mesmo porque o agronegócio vem se expandindo e com o aumento da produção de alimentos há a degradação do ambiente por falta de controle e preservação do solo. (professora da Educação Infantil. 12/04/2019).

A Educação Ambiental para rever conceitos, valores e despertar nos alunos a visão crítica da realidade vivenciada. Fazê-las repensarem os hábitos de consumo, valores $e$ atitudes de promover mudanças cognitivas e comportamentais visando a uma melhor qualidade de vida com saúde é cidadania. (professora do ensino fundamental I. 12/04/2019).

Para Carola e Cabral (2013), prevalecer o acesso à informação a contento de melhorá-la e assim aos aspectos de defesa para com a natureza seja no modo de recriar e defender medidas punitivas, e ou também aos modos de proteção e estimulação das crianças dos sentimentos que surtam efeitos nas ações e práticas de proteção,

não se contenta apenas com a criação de uma legislação de proteção à natureza, defende a criação de medidas de fiscalização e punição rigorosa aos infratores e a realização de campanhas educacionais para estimular nas crianças, sentimentos de amor e proteção à fauna e flora brasileira e propõe um conjunto de atividades educativas que comparadas com as políticas atuais podem ser considerado como a primeira versão de um programa de Educação Ambiental para o Brasil (CAROLA; CABRAL, 2013, p. 864). 
O ensino de EA está na prática pedagógica entendida, segundo Gimeno Sacristán (1999, p.74), como "[...] toda a bagagem cultural consolidada acerca da atividade educativa, que denominamos propriamente como prática ou cultura sobre a prática.". O estudante mediante o trabalho com 0 reconhecimento da temática ambiental pode associar as relações escolas comunidade e abranger as diversidades sociais culturais e as variedades de modo de vida dos muitos grupos em meio à sociedade em que vive.

Desse modo, promover o,

fazer pedagógico, dentro ou fora da escola, deve ser acompanhado de investimentos em pesquisas, na formação de professores bem preparados e na reestruturação de ideologia que permeia a escola, em todos os níveis de ensino, e a sociedade atual [...] (LISBOA; KINDEL, KROB, 2012, p. 15).

Demonstrar atos e poder transformá-lo em um ser crítico e formador de opinião são pressupostos presentes nas práticas educativas. Atitudes como o reconhecer, trabalhar e lidar com o meio ambiente é que se diversifica e torna essencial e importante o trabalho com um tema relacionado com disciplinas regulares.

Um educador que reconhece a amplitude que tem o ensino de EA desenvolve em sua prática de sala de aula um contexto que poderá atribuir com novos hábitos e, assim, para o desenvolvimento de modos de se alimentar e, cuidar-se.

Sobre o ensino de Educação Ambiental e educação alimentar questionou-se, de que modo estão relacionadas às práticas:

O cuidado com o solo, as plantações, o uso de agrotóxico e o lixo, tudo que envolve o consumo humano se refletirá com a preservação e o cuidado com o meio ambiente, pois além de se relacionarem, sempre irão causar impactos direta ou indiretamente ao meio ambiente (professora da Educação Infantil. 12/04/2019).

Segundo Mello e Farias, "em outras palavras, a convivência das crianças pequenas com as formas mais elaboradas da cultura é condição necessária - ainda que não seja suficiente - para a formação das máximas possibilidades humanas nas crianças" (MELLO; FARIAS, 2010, p. 57). Conforme Lisboa, Kindel e Krob (2012) acrescente componente ambiental tomando o como elemento significativo para a nossas "práxis".

A Educação Ambiental e seus pressupostos estão presentes no dia a dia do ser humano. Dessa forma, o convívio e as práticas do estudante em Revbea, São Paulo, V. 15, № 5: 109-123, 2020. 
vista ao seu procedimento com o meio ambiente também pode ser uma temática abordada nas aulas, às relações do sujeito mediante o estudo da temática de meio ambiente, articulada nas propostas de ensino para a educação infantil e o fundamental.

A criança aprende e transmite à família as informações e conceitos de uma alimentação saudável associada à preservação e à regeneração do meio ambiente assim, a família incorpora a mudança de comportamento e postura, auxiliando a criança em sua reeducação alimentar (professora do ensino fundamental I. 12/04/2019).

Segundo Santos e Mello (2018, p. 106) destacam o "decreto n. ${ }^{\circ} 7273$, de 25 de agosto de 2010", apresentando o objetivo deste para com o direito de uma alimentação adequada, a segurança nutricional para com a alimentação. Expõem Santos e Mello que "o direito a uma alimentação saudável e nutricional não deva comprometer 0 atendimento as demais necessidades fundamentais, promovendo práticas alimentares saudáveis [...]" deste modo, acrescentam ainda "a contribuição da alimentação escolar para a permanência do educando na escola e, assim, para a garantia de um percurso educativo mais digno". (2018, p. 106).

Segundo Goergen (2010), um valor infinito, e dos valores supremos da vida, nessa teoria de natureza intersubjetiva. Tem como objetivo, desenvolver potencial emancipatório de sua história de vida, de seus interesses, seus valores, e é preciso que, um processo de regulação, comece a compensar as diferenças, ou as insuficiências do sistema assimilador e sociais da realidade tanto no aporte, material e estrutural quanto social.

As informações contextuais, presentes na entrevista semiestruturada, nos permitiu saber como são para os alunos de educação infantil e do fundamental I, desenvolvidos o ensino de Educação Ambiental como abordagem e conteúdos sobre a educação alimentar no contexto, para o desenvolvimento relatam as professoras como se dá a prática pedagógica na escola,

através da horta escolar onde é trabalhado o desperdício de água, o uso de agrotóxico e os alimentos saudáveis que são servidos nas refeições feitas na escola, onde a unidade desenvolveu um projeto que o uso orgânico e natural são utilizados na aplicação das hortaliças, tornando os alimentos saudáveis que irão diretamente para a mesa. (professora da Educação Infantil. 12/04/2019). 
Segundo Dias (2004, p. 98) nos apresenta um panorama sobre como era concebido a EA e o meio ambiente discorrendo que, "a evolução dos conceitos de EA esteve diretamente relacionada à evolução do conceito de meio ambiente e ao modo como este era percebido". Dias acrescenta ainda em sua análise sobre o conceito que "meio ambiente, reduzido exclusivamente a seus aspectos naturais, não permitia apreciar as interdependências nem a contribuição das ciências sociais e outras à compreensão e melhoria do ambiente humano" (2004, p. 98).

\begin{abstract}
Alertar a respeito da falta de limite do homem com a natureza (solo) é com a saúde (alimentação) O que sê pretende é transmitir informação, conhecimento e conscientização à criança, através de trabalhos educativos, mostrando ser possível reencontrar-se o equilíbrio perdido entre a natureza é o homem" (professora do ensino fundamental I. 12/04/2019).
\end{abstract}

De acordo com o pensamento de Araújo (2009, p. 61), "torna-se crucial viabilizar, no espaço escolar, discussões acerca da problemática ambiental, buscando estratégias para integrar o aluno com o meio ambiente para conhecê-lo em suas múltiplas dimensões". Goergen (2010) ressalta o agrupamento das práticas educativas em suas várias categorias sobre o desenvolvimento da sociedade contemporânea, conceitua as fases em que perpassa a identidade social, estabelece relações no reconhecimento do outro, a alteridade e desenvolvimento de ações específicas um novo conceber do ser humano.

Segundo Araújo (2009, p. 62), "trabalhar com Educação Ambiental requer posicionamentos que concorram para a construção de relações mais éticas com as demais espécies biológicas e com nossa própria espécie". Para Libâneo (2011, p. 88) "em outras palavras, o ensino satisfatório é aquele em que o professor põe em prática e dirige as condições e os modos que asseguram um processo de conhecimento pelo aluno". Para Goergen (2010, p.55) "o agir comunicativo, diálogo e educação", demonstram que, "a educação, que é expressão clara desse contexto, também vive um momento de profundas transformações", as dificuldades encontradas nos atos educativos, mediante o que atribui a ciência, não podem ser modificadas e nem retalhadas à mercê de subjetividades análogas, para decisões de planejamento e pressuposto de ações submergidas aos aspectos subjetivos.

Notar a escola, como espaço comunicativo de ação pedagógica, orientada para a formação de competências, remete ao fazer pedagógico o ensino e vivência em sala de aula a Educação Ambiental e seus conceitos, sensibilizar o estudante por meio da prática educativa, sendo este o arcabouço de um professor. 


\section{Conclusões}

Esta pesquisa buscou apontar quais são as práticas pedagógicas para o ensino-aprendizagem no desenvolvimento de Educação Ambiental sobre educação alimentar, para os alunos de escola pública de ensino infantil e fundamental I. Especificamente, considerando os pressupostos das Leis, Políticas, Programas e projetos no âmbito Nacional, Estadual e municipal para a Educação Ambiental e Alimentação Escolar que em suas especificidades explicitam ações educativas voltadas à promoção do ensino-aprendizagem nas práticas pedagógicas de EA no âmbito educativo.

As práticas educativas introduzidas como propostas interdisciplinares, entre os processos educativos, abrangem possibilidades ao estudante de construir e apreciar o mundo a sua volta. A ampliação dos horizontes para com a construção, seja ela por intermédio do desenvolvimento de habilidades ou através de práticas educativas, são formas significativas para o ensino e aprendizagem contribuindo desse modo para o desenvolvimento cultural e a bagagem educacional do estudante.

A educação alimentar e nutricional como parte do ensino de EA propõe que se construa o "bem-viver", assim a segurança alimentar para as gerações futuras. Saber como se relacionar em meio a tantos problemas ambientais são temáticas trabalhadas nos temas transversais, pois, as diferentes relações sociais abordadas no estudo apresentam a complexidade de fatores e a realidade das expressões culturais.

Portanto, o trabalho promove a relação entre o meio natural e social (EA e Educação Alimentar) contribuindo com a integração dos alunos e professores, buscando um melhor aproveitamento onde eles poderão conjuntamente delinear a relação de ensino e aprendizagens presentes no contexto das duas escolas.

\section{Agradecimentos}

Às professoras partícipes que no chão da sala de aula com muito afinco torna o fazer pedagógicos possíveis reflexões;

À Coordenação de Aperfeiçoamento de Pessoas de Nível Superior Brasil (CAPES) - Código de Financiamento 001 pelo apoio financeiro à pesquisa;

À Universidade do Estado da Bahia, por tornar possível o amestramento da autora. 


\section{Referências}

ACOSTA, A. O bem viver: uma oportunidade para imaginar outros mundos / Alberto Acosta. Tradução de Tadeu Breda. São Paulo: Autonomia Literária, Elefante, 2016. 264 p.

ARAÚJO, V.R.D. Educação Ambiental no contexto escolar: Saberes e práticas docentes. Salvador: EDUNEB, 2009.

BARDIN, L. Análise de conteúdo (L. de A., Rego \& A. Pinheiro, Trads.). Lisboa: Edições 70. (2006). (Obra original publicada em 1977).

CAROLA, C.R.; CABRAL G.S. Concepções de natureza e sensibilidade ambiental nos livros didáticos de História Natural (1934-1971) Revista Brasileira de Estudos Pedagógicos / Instituto Nacional de Estudos e Pesquisas Educacionais Anísio Teixeira. v. 1, n. 1, (jul. 1944 -). - Brasília: O Instituto, 1944 -. volume 94, número 238 set./dez. 2013.

CONFERÊNCIA MUNDIAL SOBRE O MEIO AMBIENTE HUMANO.
Declaração de Estocolmo,
<http://www.direitoshumanos.usp.br/index.php/Meio-Ambiente/declaracao-de-
estocolmo-sobre-o-ambiente-humano.html>. Acesso em: 14. abr. 2019.

DIAS, G.F. Educação Ambiental: princípios e práticas. São Paulo: Gaia, 2004. GIL, A. C. Métodos e técnicas de pesquisa social. São Paulo: Atlas, 2006. GIMENO SACRISTÁN, J. Poderes instáveis em educação. Porto Alegre: ARTMED Sul, 1999.

GOERGEN, P. (Org.) Educação e diálogo, Maringá: Eduem, 2010. 274 p. Textos de Pedro Goergen - Educação e Diálogo e Luiz Roberto Gomes - Agir comunicativo, diálogo e Educação.

LAKATOS, E.M.; MARCONI, M.A. Técnicas de Pesquisa. SP: Atlas, 1982.

LIBÂNEO, J.C. Didática e trabalho docente: a mediação didática do professor nas aulas. In: LIBÂNEO, J.C.; SUANNO, M.V.R.; LIMONTA, S.V. (org.). Concepções e práticas de ensino num mundo em mudança: diferentes olhares para a didática. Goiânia: CEPED/Editora PUC Goiás, 2011.

LIMA, S.C. et al. (orgs.). Segurança Alimentar e Nutricional na Comunidade dos Países de Língua Portuguesa: Desafios e Perspectivas. Rio de Janeiro, Oficina de Segurança Alimentar e Nutricional na CPLP-World Nutrition Rio2012.

LISBOA, C.P. et al.(orgs.). Educação Ambiental: da teoria à prática. Porto Alegre: Mediação, 2012. 144p

MELLO, S.A.; FARIAS, M.A. A escola como lugar da cultura mais elaborada. Educação (UFSM), Santa Maria, p. 53 - 68, maio 2010. ISSN 1984-6444. Disponível em: $<$ https://periodicos.ufsm.br/reveducacao/article/view/1603>. Acesso em: 14 abr. 2019. 
OSÓRIO, M.R.V. Professores e Educação Ambiental: implicações para o currículo. Revista Brasileira de Estudos Pedagógicos / Instituto Nacional de Estudos e Pesquisas Educacionais Anísio Teixeira. v. 1, n. 1, (jul. 1944 ). - Brasília: O Instituto, 1944 -. volume 92, número 231 maio/ago. 2011.

ORGANIZAÇÃO DAS NAÇÕES UNIDAS. Declaração de Estocolmo sobre o Meio Ambiente Humano. In: Universidade de São Paulo, BIBLIOTECA VIRTUAL DE DIREITOS HUMANOS Conferência das Nações Unidas sobre Meio Ambiente Humano, $1972 . \quad$ Disponível em: $<$ http://www.direitoshumanos.usp.br/index.php/Meio-Ambiente/declaracao-deestocolmo-sobre-o-ambiente-humano.html.> Acesso em: 14 abr. 2019.

RICHARDSON, R.J. Pesquisa social: método e técnicas. 3 ed. São Paulo: Atlas, 2008.

ROOS, A; BECKER, E.L.S. Educação Ambiental e Sustentabilidade. Revista Eletrônica em Gestão, Educação e Tecnologia Ambiental. REGET/UFSM, na 5, p. 857-866, 2012.

SANTOS E.S.; MELLO, M.A.G.M. O programa Nacional de Alimentação Escolar (PNAE): um estudo de caso na Escola Municipal Governador Roberto Santos no município de Salvador - BA. In: MUTIM, A.L.B.; SANTOS, A.O.C. Educação profissional, território e sustentabilidade. Curitiba: CRV, 2018.

TRICHES, R.M.; SCHNEIDER, S. Alimentação escolar e agricultura familiar: reconectando o consumo à produção. Saúde soc., São Paulo, v. 19, n. 4, p. 933-945, dez. 2010. 